\title{
Nephrogenic Rest
}

National Cancer Institute

\section{Source}

National Cancer Institute. Nephrogenic Rest. NCI Thesaurus. Code C88537.

Remnants of nephrogenic blastema cells in the kidney following embryonic development. 